\title{
«LA SUPERIORIDAD MORAL DE LA MUJER»: SOBRE LA NORMA RACIALIZADA DE LA FEMINEIDAD EN CHILE (1)
}

\author{
ANTONIETA VERA GAJARDO \\ Universidad Alberto Hurtado \\ mverag@uahurtado.cl
}

(Recepción: 12/02/2015; Revisión: 28/07/2015; Aceptación: 23/11/2015; Publicación: 02/12/2016)

\begin{abstract}
1. INTRODUCCIÓN.- 2. LA CONSTRUCCIÓN DEL GÉNERO Y LA «RAZA» POR EL ESTADONACIÓN. 2.1. DE LA «DEGENERACIÓN DEL MESTIZAJE» AL ORGULLO DE LA «SÍNTESIS MESTIZA». 2.2. LA NATURALEZA DIFERENTE Y COMPLEMENTARIA DE LOS SEXOS.-3. DE LA «FALLA» A LA «SUPERIORIDAD MORAL». 3.1. CiVILIZADORAS. 3.2. EL DisCURSO FEMINISTA DE «LA SUPERIORIDAD MORAL DE LA MUJER».-4. «LA SUPERIORIDAD MORAL DE LA MUJER» COMO NORMA RACIALIZADA DE LA FEMINEIDAD EN CHILE.-5. BIBLIOGRAFÍA
\end{abstract}

\section{RESUMEN}

El presente texto problematiza las condiciones históricas de emergencia del «discurso de la superioridad moral de la mujer», una retórica de la femineidad legítima en Chile según la cual existiría un conjunto de cualidades «propiamente femeninas» que vendrían a humanizar, renovar y limpiar el espacio público y la política. Sostendré que las principales configuraciones sociohistóricas en las que emerge este discurso, se corresponden con la proliferación de debates públicos en torno al género, la raza y la nación, a fines del siglo XIX y comienzos del siglo XX.

En la primera sección del artículo, presentaré la configuración nacionalista en la cual emergería el imaginario sexo-racializado de «la familia nacional». En el segundo apartado, expondré algunas de las prácticas discursivas de alterización que responden al llamado de la misión civilizadora, entre las cuales la figura racializada de «la madre

(1) Este texto corresponde a una parte de mi tesis doctoral redactada en formato de conferencia en el marco del Proyecto Anillos en Ciencias Sociales y Humanidades, «Normalidad, Diferencia y Educación» (SOC1103). Este cuenta con el financiamiento del Programa de Investigación Asociativa-Comisión Nacional para la Investigación Científica y Tecnológica (PIA-CONICYT). Las ideas expresadas son responsabilidad exclusiva de la autora y no representan aquellas de la Comisión. 
popular» ocupa un lugar central para comprender la emergencia del discurso de «la superioridad moral de la mujer» en el Chile de la época. Finalmente, sugeriré algunas conclusiones que proponen una mirada de extrañamiento y desnaturalización en relación a «la normalidad no marcada» de la categoría «mujer» en Chile.

Palabras clave: Moral; femineidad; raza; nación.

\title{
"THE MORAL SUPERIORITY OF THE WOMAN": ABOUT THE RACIALIZED STANDARD OF FEMINITY IN CHILE
}

\begin{abstract}
This article problematizes the historical conditions of emergence of the «discourse of moral superiority of women», rhetoric of legitimate femininity in Chile under which there would be a set of «properly feminine» qualities that are here to humanize, renovate and clean the public space and politics. I will argue that the main sociohistorical configurations in which this discourse emerges, correspond to the proliferation of public debates around gender, race and the nation in the late nineteenth and early twentieth century.

In the first section of the article I will present the nationalist configuration in which sex-racialized imagery of «national family» would emerge. In the second section, I will discuss some of the discursive practices of othering who answer the call of the civilizing mission, including the racialized figure of «the popular mother» that takes the central place to understand the emergence of the discourse of «the moral superiority of the woman» in Chile at the time. Finally, I will suggest some conclusions proposing a look of bewilderment and denaturation in relation to «the unmarked normal» of the category «woman» in Chile.
\end{abstract}

Keywords: Moral; femininity; race; nation.

$$
* \quad * \quad *
$$

\section{INTRODUCCIÓN}

Las investigaciones que dieron origen a la pregunta que aborda este escrito, apuntaban a los usos estratégicos de las representaciones hegemónicas de la femineidad por parte de mujeres políticas en el Chile contemporáneo (2). Apartir de los restultados de esa búsqueda, el presente texto se pregunta por las condiciones históricas de emergencia de lo que denomino «el discurso de la superioridad moral de la mujer en Chile»: una serie de retóricas según las

(2) VERA $(2007,2009)$. 
cuales existiría un conjunto de cualidades «propiamente femeninas» (la proximidad, el cuidado de la vida, la capacidad de mediación, etc.) que vendrían a humanizar, renovar y limpiar el espacio público y la política. No se trataría, evidentemente, del único discurso sobre «la mujer» que ha circulado en la arena política, sino que del discurso hegemónico sobre la femineidad legítima en Chile. Tampoco sería un discurso excepcional en la historia del feminismo moderno, tal como lo muestra en detalle el trabajo de Joan Scott sobre el caso francés (3). Otro ejemplo lo constituyen los discursos del maternalismo político desplegados por el feminismo latinoamericano, los cuales también portarían esta marca aporética (4) entre igualdad y diferencia.

A partir del análisis del discurso de «la superioridad moral de la mujer», este trabajo reflexionará sobre las especificidades de tal aporía para el caso chileno. Sostendré que las principales configuraciones sociohistóricas en las que emerge este discurso se corresponden con la proliferación (a fines del siglo XIX y comienzos del siglo XX) de debates públicos en torno al género, la raza y la nación. De manera más específica, afirmaré que la emergencia del discurso de «la superioridad moral de la mujer» depende del mutuo modelamiento de dos eventos discursivos (5) que despliegan dos transformaciones representacionales: la del mestizaje (de la «degeneración» al orgullo racial) y la de «la mujer» (de la «falla» a la superioridad moral).

En términos teórico-metodológicos, he utilizado el análisis crítico del discurso. Desde este enfoque que se nutre de tradiciones de pensamiento heterogéneas, entenderemos el discurso como una práctica (y no como simple descripción o reflejo de la realidad) y en esa medida, como productor de realidad social (6). El análisis propiamente tal, se concentró en las dinámicas discursivas en conflicto, en sus contextos de producción, en las posiciones de los sujetos y en sus estrategias representacionales (7). La construcción del corpus sobre los debates hegemónicos de la época en torno al género, la raza y la nación, respondió a dos criterios: a) debían haber sido emitidos desde una posición públicamente reconocida; b) los objetos de sus «luchas representacionales» debían ser recurrentes. En la medida en que se trata de voces generalmente hegemónicas y públicas (periódicos, revistas, ensayos, cartas en las voces de médicos, letrados y feministas), no es la originalidad de las fuentes sino que el análisis discursivo desde el eje temático género-raza-nación, lo que interesa destacar.

(3) Desafiando una historia lineal, evolutiva y mesiánica del feminismo, Scott muestra la «ciudadanía paradójica» encarnada por cuatro feministas sufragistas francesas entre 1789 y 1944 quienes -en sus luchas por la igualdad política- revalidan el argumento de la diferencia sexual, sin subvertir los términos a través de los cuales este ha definido a «la mujer». ScOTT (1998).

(4) LAVRÍN (1995); NERI (2004).

(5) SCOTT (2001).

(6) Foucault (1969); Butler (2006); Hall (2010); VAn DiJK (2003).

(7) Procesos discursivos «que no son señalados, y que de hecho consiguen su efecto porque pasan desapercibidos». Spivak en ScOTT (2001): 64. 
En el primer apartado, presentaré la configuración histórica en la cual emerge el imaginario género-racializado (8) de «la familia nacional». En la segunda sección, expondré el discurso de «la superioridad moral de la mujer» como una práctica de alterización que responde al llamado de la misión civilizadora. Finalmente, sugeriré algunas conclusiones que proponen una mirada de extrañamiento y desnaturalización en relación a «la normalidad no marcada» (9) de la categoría mujer en Chile.

\section{LA CONSTRUCCIÓN DEL GÉNERO Y LA «RAZA» POR EL ESTADO-NACIÓN}

La época que va entre fines del siglo XIX y comienzos del siglo XX es de vital interés en la conformación de nuestras naciones latinoamericanas. Por una parte, participando del imaginario moderno que los concibió como garantes de la unidad nacional, se consolidaban los jóvenes Estados-nación, que vendrían a representar al gestionador del orden sobre el caos impartido por ese «monstruo de múltiples cabezas»: la heterogeneidad de los intereses individuales (10). Por otra parte, proliferan en Europa y Estados Unidos una serie de discursos científicos sobre la raza y el sexo que fueron bien recepcionados en América Latina y que pensaron de manera íntimamente vinculada las cuestiones de la diferencia sexual, la reproducción del pueblo y el progreso de la nación (11).

Tal como sostiene Neri, refiriéndose al auge de estos discursos científicos, lo que es específico para América Latina es que los procesos de independencia también eran recientes. Además, en el contexto de conflicto entre liberales y católicos, la ciencia pasó a representar un signo de secularización, modernismo y progreso para los intelectuales latinoamericanos. Junto con esta impronta de prestigio, los discursos científicos fueron particularmente influyentes en la representación de la raza y el sexo justamente en la medida en que se trataba de un lenguaje sobre «la naturaleza» que se proclamaba objetivo y neutro, fijando con ello los límites de lo verdadero (12). Es por todo lo anterior que las ideas científicas de la época devienen «una de las herramientas más significativas para la formación de la nacionalidad en América Latina» (13).

Entendiendo que los proyectos modernos de comunidad nacional tienen género y apelan a la idea de «unidad racial» (14), al momento de historizar la

(8) Me refiero al carácter problemático y construido de la raza, a partir de la histórica fabricación de significados y percepciones en torno a la pigmentación de la piel. MURJ y SOLOMOS (2005).

(9) Haraway (1995).

(10) VARIKAS (2007).

(11) LeYs StePAN (1991); GRAHAM (1990); LAVRÍN (1995).

(12) Leys STEPAN (1991); MÁrquez Bretón (1982).

(13) NERI (2004): 103.

(14) McClintock (1993); Yuval-Davis y Anthias (1989); Walby (2000); Varikas (2007). 
categoría «mujer» en Chile se hace necesario indagar en esta relación fundante entre ideas científicas y nacionalidad. Concretamente, pensando en las relaciones de semejanza y reciprocidad entre el modelo de familia burguesa heterosexual y el imaginario de comunidad nacional, interrogaremos el carácter racializado y generizado de la representación hegemónica de «la familia nacional» en Chile.

\subsection{De la «degeneración del mestizaje» al orgullo de la «síntesis mestiza»}

A fines del siglo XVIII, la élite mestiza latinoamericana era culturalmente dependiente de Europa y Estados Unidos. De hecho, las revoluciones francesa y estadounidense fueron reconocidas fuentes de inspiración para los «criollos liberadores» (15). Durante el siglo XIX y tal como en otras latitudes, las configuraciones nacionalistas nos muestran la productividad de los discursos modernos a partir de los cuales la biología irrumpe en la comprensión de lo social, transformando al argumento de «la naturaleza» en legitimación política de la desigualdad (16). Así, posteriormente a los procesos de independencia, las élites siguieron las teorías del racismo científico, las cuales les permitían identificarse como «blancas», escapando con ello al humillante y generalizado diagnóstico acerca del mestizaje. Efectivamente, teóricos europeos que influyeron decisivamente entre los intelectuales latinoamericanos (como Gustave Le Bon o Louis Agassiz), no reservaban un lugar de prestigio para las «razas híbridas», cuya supuesta tendencia era la degeneración, entendida como progresivo «empeoramiento racial». Otros, como Joseph Arthur de Gobineau y Paul Broca, enfatizaron en la necesidad de controlar «los buenos»y «malos mestizajes»: estos últimos serían ilustrados por «el caso latinoamericano». Así, en términos generales, las teorías raciales europeas diagnosticaron «la terrible heterogeneidad mestiza» de América Latina, entendiéndola como falta de «coherencia biológica» y de «identidad estable». Aquello condenaría a esas naciones híbridas a la incapacidad para el progreso y la modernización (17).

Sin embargo, a comienzos del siglo xx, los diagnósticos deterministas con respecto a la «degeneración racial latinoamericana», serán desafiados. En esta línea y focalizándose en los discursos eugenistas, Leys Stepan propone la idea de un latin style, afirmando que de manera diferente a lo que ocurrió en gran parte de Europa, las teorías científicas en torno al «mejoramiento de la raza» pusieron el énfasis en un enfoque más neolamarckiano que mendeliano, lo que en términos sociales implicó que las políticas públicas latinoamericanas se caracterizarían por un tono ambientalista focalizado esencialmente en la

(15) Helg (1990); ANDERSON (1993).

(16) VARIKAS (2007).

(17) GRAHAM (1990); LeYS STEPAN (1991); LAVRín (1995). 
prevención. Según la autora, uno de los factores que más influyó en la consolidación de este enfoque fue su mirada política optimista: influyendo en el medio social sería posible arribar a un perfeccionamiento progresivo de la raza. Así, las condiciones ambientales que estarían a la base de la «degeneración», los llamados venenos raciales (alcohol, tabaco, pestes, enfermedades venéreas, etc. ), constituirán el eje de acciones sociales, pedagógicas y médicas. De esta manera y también considerando el desarrollo de las ciencias bacteriológicas y microbiológicas que desde fines del siglo XIX prometían erradicar las grandes pestes, el grupo profesional de los médicos adquiere un prestigio determinante para el Estado, especialmente en aquellos países (como los latinoamericanos) en los que las ansiedades en torno a «la cuestión social» inspiraron discursos de «crisis nacional» (18).

Junto con los médicos, la figura del «letrado» cumplió un rol central en la formación de las Repúblicas latinoamericanas, especialmente a partir de los debates sobre «la identidad nacional» (19). Los procesos de modernización y el consecuente ambiente de competitividad entre países, fueron favorables al despliegue de retóricas nacionalistas entre las cuales la comparación entre los «niveles de progreso» de Estados Unidos y el resto de las naciones americanas, se hacía evidente. Entendiendo que en esta época, la idea de «raza» era inevitable al momento de buscar explicaciones a casi cualquier evento social (20), una respuesta reiterativa entre los intelectuales latinoamericanos fue justamente que Estados Unidos era un país más avanzado porque había sido construido a partir de la inmigración anglosajona, y porque negros e indígenas habían sido segregados. Consecuentemente, fomentar el «blanqueamiento» a través de la inmigración europea, se concibió como la clave de la modernización y el progreso latinoamericano (21).

Sin embargo, si el nacionalismo de la segunda mitad del XIX se caracterizó por un discurso dependiente de los valores culturales de Europa, por la exterminación de los no-blancos y por las campañas de blanqueamiento a través de la inmigración europea, los comienzos del siglo $\mathrm{XX}$-marcados en gran medida por la revolución mexicana (22)- mostraron un nuevo énfasis discursivo de carácter

(18) LEYS STEPAN (1991).

(19) RAMA (2009); CASTRO-GÓMEZ (1996).

(20) Leys Stepan (1991); Graham (1990).

(21) Helg (1990); Leys-StePan (1991). El caso argentino fue paradigmático. Durante el siglo XIX, los principales defensores del blanqueamiento fueron Domingo Faustino Sarmiento, Carlos Octavio Bunge y José Ingenieros. Según la perspectiva de Sarmiento, desarrollada fundamentalmente en Facundo o Civilización y barbarie en las pampas argentinas (1845) y en Conflicto y armonía de las razas en América (1883), el escalón racial más bajo no era ocupado por los negros (a quienes consideraba una raza infantil que «Dios había reservado para otros mundos»), sino que por los indígenas, caracterizados por su alcoholismo congénito, pereza e ignorancia de las «virtudes civilizadas» como la propiedad privada, el libre emprendimiento y la democracia. Helg (1990): 40.

(22) KNIGHT (1990). 
anti-imperialista y crítico de las influencias extranjerizantes (23). En efecto y tal como lo sostiene Leys Stepan, tanto el consenso en torno a la necesidad de unión nacional frente a los conflictos sociopolíticos, como el deterioro de la imagen de «la Europa civilizada» a partir de la expansión de su propia «barbarie» durante la primera guerra mundial, fueron factores que llevaron a los intelectuales latinoamericanos a cuestionar la necesaria homologación entre hibridez racial e inferioridad y con ello, a proponer reconceptualizaciones del mestizaje. De este modo, los discursos pro-blanqueamiento racial coexistirán de forma tensionada con retóricas que pusieron en cuestión la superioridad racial del blanco y que rechazaron la penetración política, económica y cultural de Estados Unidos y Europa.

Así y aun considerando las particularidades de cada contexto nacional, es posible afirmar que uno de los eventos discursivos de esta época fue una reapropiación positiva del estigma racial. La retórica de la «impureza mestiza» propia del racismo científico, será tensionada (nunca totalmente extinguida) por diferentes reconceptualizaciones positivas del mestizaje que implicarán una transformación de la valoración política y moral de la figura (paradigmáticamente masculina (24)) del «mestizo». En términos generales, estas reconceptualizaciones coincidieron en la defensa de una «síntesis mestiza»: fusión racial, tipo biológico-cultural homogéneo y racialmente superior, representante de la mezcla de los mejores «ingredientes raciales» de cada nación, «diferencia latinoamericana» $(25)$.

Castro-Gómez sostiene que pensadores como el mexicano José Vasconcelos o el peruano Antenor Orrego fueron representantes de una corriente filosófica mesiánica que a través de categorías como «pueblo» o «nación», buscó identificar los orígenes de «la diferencia latinoamericana». El autor señala que los letrados de esta época popularizaron el diagnóstico de una Europa envejecida versus una Latinoamérica joven y revitalizada por un mestizaje inédito. En palabras de Orrego (26): «un nuevo amasamiento de sangres... una nueva unificación biológica, anímica y espiritual» (27) a partir de la cual Latinoamérica

(23) Hobsbawm (2010). Evidentemente, este giro discursivo no se expresará de manera homogénea en todos los países latinoamericanos. Así por ejemplo, en el caso de Argentina, el discurso hegemónico distinguirá más bien entre los «buenos» (anglosajones) y los «malos» (mediterráneos, judíos, etc.) inmigrantes europeos, «cuya capacidad de asimilarse al estilo de vida argentino era profundamente puesta en duda por la antigua élite». LEYS STEPAN (1991): 140.

(24) BOIDIN (2008)

(25) Graham (1990); ZermeÑo-Padilla (2008).

(26) En 1930, el filósofo Antenor Orrego (1892-1960) era uno de los fundadores del Partido Aprista Peruano (APRA) cuya propuesta inicial, según el pensamiento de Haya de la Torre, era conformar una red de movimientos sociales antiimperialistas. El pensamiento latinoamericanista de Orrego (bien representado en Pueblo Continente, de 1937) abogará por un «nacionalismo continental» cuyo liderazgo espiritual debiese estar en manos de las élites intelectuales, en pos de la misión histórica del continente: la unidad universal. PAKKASVIRTA (2005); CASTRO-GÓMEZ (1996)

(27) En CASTRO-GÓMEZ (1996): 80. 
tendría «la misión de hacer avanzar al mundo hacia una cultura 'unitaria e integral'», incluso, hacia una «nueva eticidad» (28).

Por su parte, en 1925, Vasconcelos (29) afirmaba:

Comienza a advertirse este mandato de la Historia en esa abundancia de amor que permitió a los españoles crear una raza nueva con el indio y con el negro [...] La colonización española creó mestizaje; esto señala su carácter, fija su responsabilidad y define su porvenir. El inglés siguió cruzándose sólo con el blanco, y exterminó al indígena [...] Esto prueba su limitación y es el indicio de su decadencia [...] La predestinación de América obedece al designio de constituir la cuna de una raza quinta en la que se fundirán todos los pueblos, para reemplazar a las cuatro que aisladamente han venido forjando la Historia [...] Y se engendrará de tal suerte el tipo síntesis que ha de juntar los tesoros de la Historia [...] Los muy feos no procrearán, no desearán procrear, ¿qué importa entonces que todas las razas se mezclen si la fealdad no encontrará cuna? La pobreza, la educación defectuosa, la escasez de tipos bellos, la miseria que vuelve a la gente fea, todas estas calamidades desaparecerán del estado social futuro [...] Lo cierto es que el vigor se renueva con los injertos y que el alma misma busca lo disímil para enriquecer la monotonía de su propio contenido [...] América es la patria de la gentileza, la verdadera tierra de promesa cristiana [...] Nos hemos educado bajo la influencia humillante de una filosofía ideada por nuestros enemigos [...] De esta suerte nosotros mismos hemos llegado a creer en la inferioridad del mestizo (30).

Las ideas de Vasconcelos ilustran las ambivalencias de gran parte de los discursos indigenistas y anti-imperialistas de la época. Construyendo una representación del «indígena» como «alma nacional» localizada en un pasado incorpóreo y ubicando al «mestizo» como ciudadano portador de ese pasado y a la vez futuro de la nación, muchos de estos discursos adquirieron una forma mestizofílica que participó del ideal asimilacionista del Estado, el cual pretendió gestionar de manera razonable y controlada «la integración del indígena» según el modelo de una «nación coherente» (31). Finalmente, la rehabilitación del «mestizo» como norma racial bipartita («poseedora de elementos indios y europeos distintivos y potencialmente separables» (32)), no solo implicó la exaltación de un tipo físico de «mestizo europeizado», sino que una serie de

(28) CASTRO-GÓMEZ (1996): 81-84.

(29) Filósofo y abogado, Vasconcelos (1882-1959) fue también el primer ministro de Educación de México (1921-1924). Junto a Franz Boas y Manuel Gamio, fue uno de los grandes ideólogos de la integración y asimilación de los indígenas fundamentalmente a partir de la educación, la cual concibió como un apostolado civilizatorio. KNIGHT (1990).

(30) Vasconcelos, J. [1925] (1958): 918-936. La Raza cósmica. Misión de la raza iberoamericana. Ciudad de México: Libreros Mexicanos Unidos (énfasis mío).

(31) Aunque la revolución mexicana de 1910 permitió visibilizar la opresión de los indígenas, estos fueron más bien el objeto y no el sujeto de un proyecto a partir del cual la figura moral del guerrero indígena oprimido por los españoles sería transfigurada en la figura del mestizo, representado como rebelde y enemigo de las élites blancas propietarias. KNIGHT (1990).

(32) KNIGHT (1990): 87. 
antipatías hacia «otra razas» (negros, chinos, etc. ) (33). Aquello explicita la comunión de estos discursos pro-defensa de «la síntesis mestiza» con algunos de los criterios productores de las representaciones racistas de la época (belleza/ fealdad, pureza/contaminación, etc.) (34).

En el caso de Chile, tal como lo subrayan pensadores de corrientes teóricopolíticas heterogéneas (35), las primeras décadas del siglo XX corresponden a un periodo de retóricas en torno a «la crisis» que abogaban por la necesidad de integración de sectores sociales y étnicos explícitamente excluidos, tanto en la colonia como durante el siglo XIX. Efectivamente, frente a los procesos contradictorios de la modernización, el miedo de las clases dirigentes a la revolución de los sectores desposeídos y a la consecuente pérdida de estabilidad política, implicará no solo la revitalización del binomio civilización/barbarie, sino que también un nuevo pacto social: un viraje histórico de políticas excluyentes a políticas inclusivas del «pueblo», ahora bautizado como «la raza» e invitado a formar parte de «la familia nacional». Esta racialización del pueblo fue clave en una época en la que la idea de unidad nacional era entendida como «unidad racial» (36): el imperativo político fue entonces reforzar «la unión (racial) y evitar la lucha (de clases)» (37). Subercaseaux señala que se desarrolla así un nacionalismo cultural moderno cuyos discursos políticos, educacionales y médicos se verán atravesados por la noción psicobiológica de «la raza chilena», paradigmáticamente expuesta en la obra homónima de Nicolás Palacios (38), publicada por primera vez en 1904.

Según Subercaseaux, el éxito de la recepción en Chile de una obra mediocre como la de Palacios dependió de eventos histórico-políticos (39) que favorecieron un ambiente nacionalista y con ello, la pertinencia de una propuesta de

(33) KNIGHT (1990) sostiene que si bien el discurso anti-imperialista de la Revolución Mexicana estuvo fundamentalmente dirigido contra «los yanquis» (estadounidenses) y «los gachupines» (españoles), el caso más claro de la xenofobia indigenista fue contra los chinos, estereotipados como sucios, enfermos, adictos a las drogas y a los juegos de azar. Así por ejemplo, defendiendo la idea de «la unidad étnica», Vasconcelos advertirá que debido a su incapacidad de asimilación -sumada a que se reproducían más rápido que los indígenas y los mestizos- «los orientales» ponían en peligro el proceso del mestizaje deseable. Es así que hacia 1930, Vasconcelos defenderá cuotas raciales de inmigración. LEYS STEPAN (1991).

(34) RUBio (1996); LEYS STEPAN (1991).

(35) Subercaseaux (2007); Illanes (2007); Arancibia (1986).

(36) VARIKAS (2007).

(37) ILLANES (2007): 208.

(38) Médico e ideólogo nacionalista clave a comienzos del siglo Xx, Palacios (1858-1927) pensaba la superioridad racial de los chilenos a partir de las ideas evolucionistas de Darwin y Spencer. Su obra inspiró el trabajo de historiadores conservadores como Francisco Antonio Encina y del Movimiento Nacional Socialista chileno durante los años 1930. SUBERCASEAUX (2007); ROBERTSON (1984).

(39) Tales como el Centenario, la Guerra Civil de 1891, el refuerzo de los sentimientos patriotas después de la Guerra del Pacífico y el malestar de las clases populares en relación al favoritismo del gobierno por los extranjeros. SUBERCASEAUX (2007). 
ciudadanía étnico-cultural más amplia que la ciudadanía política de sello liberal. Efectivamente, desde una retórica menos latinoamericanista que la vasconceliana y al igual que en el caso argentino, más partícipe de la idea de «la excepcionalidad nacional», el texto La raza chilena desarrolla en profundidad la idea de una «personalidad nacional» encarnada por la figura del «roto chileno» (40): raza mestiza privilegiada (mezcla de godos y mapuches) y homogénea («base étnica de nuestro país», «entidad racial perfectamente definida» debido a que «araucanos (41) y góticos» fueron «dos razas de corazón y cerebro semejantes» (42)).

Según Palacios, la fama de «bárbaros» de la que gozaban los godos se debió a su originario ataque a las civilizaciones greco-romanas, mundo de «letrados, sacerdotes y dioses del mediodía», «raza inferior de hombres afeminados y corrompidos» (43), que decantaría en una «sicología latina» de carácter «matriarcal» (44). Fundamentando sus afirmaciones en lo que denomina «sicología étnica» (45), el autor asevera que los godos serían, en cambio, dignos representantes de una raza de «sicología patriarcal» (46). Así, si bien la «raza chilena» poseería tanto rasgos matriarcales como patriarcales, sería la impronta patriarcal guerrera la que definirá una suerte de depuración racial en el «roto chileno». En este marco, el autor diagnostica que la crisis nacional de comienzos del siglo Xx en Chile, es ante todo una crisis moral de la aristocracia dominante que -junto con empobrecer la imagen que el pueblo tiene de sí mismo- ha sido influenciada por costumbres propias de la «raza latina». Tales costumbres

(40) Antes de las guerras contra Perú y Bolivia del siglo XIX (1836-1839 y 1879-1883), el «roto» señalaba al sujeto indócil e iletrado del bajo pueblo. Sin embargo, después de estas guerras, se populariza la idea según la cual el triunfo se debería justamente a la valentía de este sujeto popular, devenido héroe nacional. SUBERCASEAUX (2007).

(41) En esta época, «araucano» fue la designación racial para los mapuche.

(42) Palacios, N. [1904] (1918): 34-38. Raza chilena. Libro escrito por un chileno y para los chilenos. Santiago: Editorial chilena.

(43) Palacios (1918): 90.

(44) PALACiOS (1918): 297.

(45) Palacios (1918): 299.

(46) El autor explica: «Sabido es por todos que la familia es la piedra fundamental de la sociedad [...] Los estudios de sicología étnica tienen hoy comprobado que en las razas de sicología patriarcal o varonil, la organización de la familia descansa en el celo sexual o egoísmo de reproducción del hombre, y que el pudor, el recato, virtudes fundamentales del grupo familiar en estas razas, deben su existencia a ese mismo celo varonil. En las razas matriarcales no siempre existe un grupo familiar bien determinado y concreto [...] las relaciones sexuales en esas razas no tienen ese núcleo vital de un solo hombre [...] Es un hecho que las mujeres de las razas matriarcales tienen más carácter, más iniciativas, son más mandonas y voluntariosas que sus hermanas de las razas patriarcales: son menos femeninas. Las mujeres de los pueblos de sicología varonil deben, como he dicho, sus virtudes domésticas al control del hombre, el cual, impulsado por su egoísmo reproductivo ha ido eliminando violentamente durante largo número de generaciones a las mujeres que no le daban una seguridad completa en sus aspiraciones de ser él solo su varón. De allí que solo hayan sobrevivido esas mujeres sumisas, devotas y fieles, que son el encanto del corazón del hombre de esas mismas razas». PALACIOS (1918): 300-301. 
provendrían fundamentalmente de la aristocracia de Santiago, y se expresarían en «piezas teatrales de carácter inmoral», bailes como el «cancán», «novelas sin más mérito que su impudicia descarada», «diarios feministas», «estatuas de sátiros y faunos» expuestas en el Museo («figuras híbridas» que «representan sencillamente una monstruosidad moral»), «poesías de género erótico [...] cultivadas por la poetisa Safo»(47), etc. La crisis se explicaría, así, por el «afeminamiento de la raza» de la cual sería responsable esta élite ociosa, decadente e inmoral que arruinaría la «base biológica de la moral sexual» (48) de la raza patriarcal chilena. Frente a aquello, la rehabilitación de la figura mestiza y viril del roto chileno debería imponerse.

Estos ejemplos ilustran un evento discursivo clave en la autoafirmación nacionalista de comienzos del siglo Xx en América Latina: el tránsito -con sus continuidades y ambivalencias- desde la ansiedad de asimilación a los valores culturales «blancos», hacia la inversión del estigma racial en «orgullo mestizo». Si bien estos discursos reeditan criterios coloniales de clasificación y jerarquización de los cuerpos, también proponen un imaginario de «familia nacional» en el que los grupos racializados por las élites «blancas» optarán a formas de reconocimiento posibilitadas por un nuevo «nosotros» mestizo.

En relación a ese «nosotros», tanto las convicciones de Vasconcelos como las de Palacios son explícitas en mostrar -tal como señala Stoler- cómo la sexualidad es capaz de construir y borrar fronteras raciales tanto a nivel metafórico (iconografía de la jerarquía) como a nivel material (los cuerpos como la substancia misma de los proyectos nacionales) (49). Efectivamente, en la medida en que la cuestión del mestizaje alude de una u otra manera al control sobre la reproducción y la sexualidad, sostendré que las ansiedades nacionales en torno al desorden sexual también modelaron los imaginarios racializados de «la familia nacional». Esto, a partir del que ha sido «el argumento maestro de la política de género de la modernidad» (50): la naturaleza diferente y complementaria de los sexos.

\subsection{La naturaleza diferente y complementaria de los sexos}

La pregunta por la relación entre identidad nacional y raza es vehiculizada por las ansiedades de los grupos intelectuales, las cuales se concentraron en un primer momento en la tesis de la «degeneración» y, posteriormente (a partir de la resignificación positiva de la síntesis mestiza), en la administración de los «buenos» $\mathrm{y}$ «malos mestizajes». El necesario control de «los úteros de la na-

(47) Palacios (1918): 319-323.

(48) Palacios (1918): 320.

(49) STOLER (2013)

(50) VARIKAS (2007). 
ción» que aquello implicaba encontró en el argumento científico de «la naturaleza diferente y complementaria de los sexos», la legitimidad necesaria para consolidar los límites biológica y políticamente incuestionables de la «familia nacional».

Identifico tres claves del argumento (la naturaleza, la complementariedad y la ambivalencia) de las cuales problematizaré fundamentalmente la última.

Laqueur sostiene que, anclado históricamente alrededor del siglo XVIII, el discurso de «la naturaleza diferente y complementaria de los sexos» marca las representaciones modernas del «hombre» y de «la mujer» con el signo de la inconmensurabilidad de la diferencia (51). La lógica del argumento sería la siguiente: la diferencia entre «el hombre» y «la mujer» sería irremediable en tanto inscrita en el «misterio» de sus naturalezas. Por lo mismo, sostiene Varikas, no sería posible cuestionar la autoridad arbitraria que sostiene la definición misma de la división sexual público-privada: se trataría de una cuestión pre-política, no de voluntad de dominación (52).

Al mismo tiempo, este argumento que ha popularizado una serie de binarismos constituyentes del pensamiento moderno hegemónico (razón/emoción, universal/particular, político/doméstico), revela el carácter constitutivamente jerárquico de la complementariedad: «en el sentido en que produce mediante la bicategorización puro/impuro, las categorías asimétricas que se supone separa y opone y que, en consecuencia, aparecen como 'ya ahí', inmutables y naturales» (53). En este sentido, «hombre» y «mujer» no existen «ni antes ni fuera de las relaciones [de poder] que los constituyen como tales» (54).

Finalmente, para problematizar el carácter ambivalente de las representaciones sobre «la mujer» producidas por este argumento, resulta ilustrador exponer algunos de los discursos médicos y letrados de la época señalada.

$\mathrm{Al}$ respecto, es importante identificar la influencia de las ideas del naturalista Charles Darwin y el éxito, en América Latina, de las interpretaciones de Herbert Spencer (55). A pesar de la crítica a la aplicación spenceriana del modelo darwinista de selección y adaptación animal-vegetal a las sociedades humanas (56), en la obra The descent of man and selection in relation to sex, publicada por Darwin en 1871, el argumento es claro: la diferencia entre las facultades mentales de los dos sexos era el resultado de un proceso de selección natural según el cual el hombre era superior a la mujer en coraje, energía, intelecto e ingenio. La mujer, en cambio, superaba al hombre en intuición, percep-

(51) LAQUEUR (1992).

(52) VARIKAS (2006)

(53) VARIKAS (2007): 105.

(54) Ibidem.

(55) GRAHAM (1990).

(56) CAngullhem (1977). 
ción e imitación, todas «características de razas inferiores y, por lo tanto, de un estado de civilización anterior y más bajo» (57).

Las ideas socialdarwinistas en torno a la división de los sexos (que pondrán especial énfasis en la incompatibilidad entre inteligencia y sistema reproductivo femenino (58)), influirán en la producción discursiva de los médicos latinoamericanos. Aludiendo al caso chileno, Zárate sostendrá que el argumento clave de los médicos de la época fue que los órganos sexuales femeninos tenían el poder de influenciar y de transformar el carácter y la conducta moral de las mujeres (59). Los hombres, en cambio, estarían exentos de esta vulnerabilidad (60). En línea con los debates europeos sobre la histeria, tales argumentos se enmarcan en una representación de la femineidad clave de la época: el binarismo «madre/mujer nerviosa» (61).

Esta fusión de lenguaje científico y moral expondrá el carácter ambivalente con el que los discursos médicos marcan la representación hegemónica de «la mujer»: la maternidad como la cara legítima de la femineidad, siempre puesta en riesgo por su inquietante «reverso nervioso»: «la histérica», «la intelectual», «la ociosa». Así podemos verlo en algunas publicaciones médicas en el Chile de la época.

En 1884, Victor Körner señalaba en su Exploración de la mujer, que los órganos genitales de la mujer «son más voluminosos que los del hombre» y de ahí «su influencia sobre su constitución y su carácter moral» (62). En 1893, Antonio Pons publicaba El estado interesante, afirmando que el estado de alie-

(57) En VENEROS (1995): 137.

(58) Tal es el caso de Sex in mind and in education, publicado en 1874 por el inglés Henry Maudsley y de Sex in education: a fair chance for the girls, publicado por el estadounidense Edward H. Clarke en 1873. Los científicos coincidían en que un esfuerzo mental sostenido alteraría la capacidad reproductiva de las mujeres, comenzando por la atrofia de los senos y concluyendo en una total esterilidad. Todo aquello implicaría tanto la producción de una criatura monstruosa - «algo que sin dejar de ser una mujer, no era todavía un hombre»-como «el suicidio de la especie humana». Maudsley en Veneros (1995): 142, énfasis mío.

(59) ZÁrate (2001).

(60) SMith-Rosenberg y Rosenberg (1973).

(61) Uno de los debates decimonónicos entre católicos y científicos que ilustra el triunfo del argumento moderno de «la naturaleza diferente y complementaria de los sexos» en Chile, corresponde al caso de Carmen Marín, «la endemoniada de Santiago». Como señala Roa (1974: 30) Carmen era una «muchacha pobre y semi alfabeta» que alrededor de 1857 había sido tratada en el Hospicio de Santiago debido a sus extraños síntomas (convulsiones, blasfemias, hablar «idiomas extraños»). Padecía, según el sacerdote José Zisternas, de una «enfermedad no natural» y «diabólica», por lo que practicó el exorcismo correspondiente. Según el doctor Manuel Carmona, en cambio, «cualquier médico verá en el cuadro el segundo grado o estadio de una pasión histérica» (en Roa, 1974: 253); "el útero es como la hidra monstruo [...] el único natural demonio que irradia sobre todo el sistema y muy particularmente sobre el cerebro sus quiméricas y vivísimas simpatías» (en Roa, 1974: 275, énfasis mío). Finalmente, será la interpretación de la naturaleza teratológica del cuerpo histérico la que triunfará por sobre el argumento teológico de la posesión demoníaca.

(62) En ZÁrATE (2001). 
nación propio de la mujer embarazada (expresado fundamentalmente en los antojos) hacía conveniente tratarla con una «paternal condescendencia» pero también aislarla si sus deseos devenían «demasiado aberrantes» (63). En Neurosis mímicas publicado en 1879, Augusto Orrego Luco sostenía que la educación viciosa y la vida ociosa, eran factores que se encontraban a la base del desarrollo de la histeria y que por lo mismo, esta enfermedad era «patrimonio de la mujer elegante, coqueta y bella» (64). En Higiene del matrimonio publicado por Pedro Monlau en 1912 y en Influencia de la cultura física en la formación del carácter. Educación física de la mujer publicado por Alfredo Moraga Porras en 1911, se sostendrá simultáneamente que «la inteligencia es inversamente proporcional a la procreación», pero que la mujer poseía asimismo «una sensibilidad mayor», «sentimientos más delicados y finos» y que era «esencialmente buena, dócil y simpática» (65). En 1914, Luis Cruz Ocampo publica El feminismo en general y sus relaciones con la legislación chilena, señalando allí que la potencia intelectual femenina solo era posible si se ponía en riesgo la maternidad: por lo tanto la igualdad entre los sexos era antinatural (66).

Reflexionando sobre el sujeto colonial, Bhabha ha pensado en la ambivalencia como una de las «estrategias discursivas y psíquicas más importantes del poder discriminatorio, ya sea racista o sexista, periférico o metropolitano» (67). La ambivalencia sería propiedad del estereotipo,

una forma de conocimiento e identificación que vacila entre lo que siempre está 'en su lugar', ya conocido, y algo que debe ser repetido ansiosamente [...] Es este proceso de ambivalencia [...] lo que [...] asegura su repetibilidad en coyunturas históricas y discursivas cambiantes; conforma sus estrategias de individuación y marginalización; produce ese efecto de verdad probabilística y predictibilidad que, para el estereotipo, siempre debe estar en exceso de lo que puede ser probado empíricamente o construido lógicamente (68).

En términos generales, la ambivalencia que marca los estereotipos raciales y sexuales de los discursos estatales invisibiliza la jerarquía gracias al poder incontestable del argumento de «la naturaleza» (69). En las descripciones médicas a las que hemos hecho alusión, «las mujeres» aparecen espirituales, pero menos inteligentes que los hombres; cercanas a lo divino, pero prisioneras de sus impulsos animales. En esa representación estereotipada coexisten la valorización y el desprecio, la idealización y el miedo, develando con ello un profun-

(63) VENEROS (1995): 148

(64) ARAYA (2006): 13.

(65) Monlau en Veneros (1995): 146; Moraga Porras en Veneros (1995): 145.

(66) Veneros (1995): 146.

(67) BНABHA (1994): 91.

(68) BНABHA (1994): 91.

(69) VARIKAS (2007). 
do desconocimiento de las experiencias concretas y heterogéneas de las mujeres de carne y hueso sobre las que se habla en tercera persona.

En el siguiente apartado me propongo mostrar algunos de los efectos de este carácter ambivalente del argumento de «la naturaleza diferente y complementaria de los sexos» a partir de su emergencia como discurso de «la superioridad moral de la mujer». Discurso al interior del cual coexisten la idealización romántica y el fantasma de aquella «hidra-monstruo» responsable de la siempre potencial falla moral femenina.

\section{DE LA «FALLA» A LA «SUPERIORIDAD MORAL»}

\subsection{Civilizadoras}

El discurso de «la superioridad moral de la mujer» alcanza un nivel decisivo de pregnancia en las primeras décadas del siglo xx en Chile, época en la que el llamado a la unidad nacional promoverá prácticas discursivas tendientes a la asimilación (70) de la otredad género-racializada encarnada por «la familia popular».

Es sobre todo la figura de «la mujer popular» la que concentrará las ansiedades de los discursos médicos y letrados. Al respecto, presento dos ejemplos: los debates en torno al mestizaje y a la higiene social.

A pesar de que en el territorio que hoy corresponde a Chile existían y existen diversos pueblos indígenas, el imaginario hegemónico del mestizaje ha aludido históricamente a los mapuche (71). La frontera entre chilenos y mapuche al sur del país, fue cediendo a partir de la independencia nacional en 1810 y del ingreso paulatino de colonos chilenos en territorio mapuche, proceso que se consolida en 1883 a partir de la ocupación militar llamada «Pacificación de la Araucanía» (72). En ese marco y contrariamente a otros proyectos nacionalistas de pureza y endogamia racial, las misiones católicas y los intelectuales nacionalistas, liberales y laicos de comienzos del siglo xx en Chile coincidirán (a pesar de sus muchas desavenencias) en el proyecto de asimilación de los mapuche vía mestizaje (73). Este proyecto implicará «un conocimiento y un

(70) Entendemos asimilación como una práctica discursiva colonial y/o estatal que produce distintas formas de mímesis y/o inclusión diferenciada del «otro». VARIKAS (2007); BHABHA (1994). En el contexto aquí analizado, la estrategia asimilacionista moviliza retóricas de unidad que coexisten con el hostigamiento y borramiento de diferencias culturales, con el objeto de producir un sujeto mestizo homogéneo de identificación nacional. ZERMEÑo-PADILLA (2008); KNIGHT (1990).

(71) García de la Huerta (1999).

(72) BENGOA (2000).

(73) Menard y PaVez (2007). 
disciplinamiento de las sexualidades en tanto materia prima e instrumento en la producción de un sujeto mestizo» (74).

La etnología mapuche del profesor normalista Tomás Guevara es un buen ejemplo de la convicción generalizada de los intelectuales de la época: la inexorable extinción de una raza inferior y la esperanza de su incorporación, vía chilenización, a la civilización (75). Estigmatizando a los mapuche como una «raza de bajo desarrollo moral», Guevara ubicará «la diferencia racial en la diferencia que opone el plano común de la animalidad sexual, el instinto y la voluptuosidad, al pudor civilizado» (76). Y será el cuerpo-metáfora de «la mujer mapuche» el que opera como representación de «su raza». En efecto, siguiendo el argumento de pensadores europeos como el psicólogo Theodule Ribot en su Ensayo sobre las pasiones de 1907, Guevara afirmará que

el pudor se desarrolla paralelamente al valor moral de un pueblo [...] Careciendo de esta base, tenía que ser embrionario en la mujer de Arauco. Ciertas manifestaciones usuales lo comprueban de sobra: bañase desnuda a presencia o cerca del hombre, descubre el pecho públicamente para lactar al niño, no se preocupa la soltera en ocultar la desnudez de su cuerpo [...] ni la casada se recata mucho para el ejercicio del acto de la generación (77).

Así, Pavez sostiene que la «amenaza erótica del cuerpo colonizado» hacia el «cuerpo burgués masculino» marcará las ambivalencias del pensamiento de Guevara quien -vinculando «científicamente» pudor a civilización- condenará la sexualidad de las mujeres mapuche al mismo tiempo que promoverá su necesaria «chilenización» (78).

Pavez también llama la atención sobre otro ideólogo del mestizaje al que ya hemos hecho alusión en relación al rol clave de la sexualidad en la personalidad de la raza: Nicolás Palacios. Este se enfrentará a los dichos de Guevara que «desconceptúan nuestro origen étnico» atacando «la más pura de las virtudes domésticas araucanas: la castidad y recato de sus esposas. [Siendo] el Araucano [...] netamente patriarcal [...] la castidad de sus mujeres es un hecho lógico y necesario» (79).

Nuestro interés no es dirimir «la verdadera» entre estas representaciones en pugna que fabrican simultáneas jerarquías entre hombres y mujeres, entre chilenos/as y mapuche y entre «mujeres civilizadas» y «mujeres impúdicas». Más interesantes resultan las funciones políticas que tales representaciones cumplen en uno u otro caso, así como sus efectos en tanto fabricación del género y la raza de la nación. Así, si en el pensamiento de Guevara la impudicia y la disponibilidad

(74) MENARD (2009): 22.

(75) MENARD (2009).

(76) Menard (2009): 22-23.

(77) Guevara, T. (1911): 177.

(78) PAVEz (2014).

(79) Pavez (2014): 33. 
de las mujeres mapuche cumple la función de justificar la misión civilizadora vía mestizaje, la defensa de la excepcionalidad de «la raza chilena» en Palacios implica una necesaria rehabilitación moral de los mapuche como «raza patriarcal», cuyo «celo sexual» sería responsable del resguardo del pudor de «sus mujeres». En ambos casos, sin embargo, el proyecto del mestizaje depende de una de las inquietudes que ha marcado la historia del nacionalismo: «¿Quién define a las mujeres?» (80). Efectivamente, es la ansiedad nacional en torno a la moral de la mujer racializada la que se presenta de manera transversal en estos discursos que imaginan «la familia nacional» como «mestiza».

Esta ansiedad también informará los debates del higienismo social de la época.

Illanes y Lavrín coinciden en afirmar que si hasta 1880 en Chile los excluidos eran fundamentalmente tratados por la caridad de la Iglesia, desde 1910 en adelante la medicina preventiva y las políticas estatales reemplazarán la caridad por «el control sobre la muerte» a través de la higiene social, encargada de hacer frente a asuntos tan diversos como los altos índices de mortalidad infantil, el hacinamiento, las pestes y las enfermedades venéreas. Así, sostienen Palacios y Leyton, «la herencia o genética de los pobres» constituirá la preocupación central de los profesionales que -asociando criminalidad, pobreza y etnicidadconstruyen al «tipo criminal» en Chile: médicos y criminólogos identificarán en la supuesta tendencia de las clases bajas al crimen, la herencia étnica (fundamentalmente mapuche) expresada en la inclinación al robo, al homicidio y a la pasión por la bebida alcohólica (81).

Esta continuidad colonialista en la figura racializada del sujeto popular, es clara en uno de los discursos de la higiene social: la puericultura (82).

Para el caso sudamericano, el contexto general en el que es necesario localizar la problemática alude al «hito corporal» (83) de la época: la tuberculosis y la mortalidad infantil eran las principales causas de muerte en el cono sur. Al respecto, Lavrín observa que para un país como Chile (que se enorgullecía de su «excepcionalidad») no debe haber sido trivial que hacia 1905 ostentase una las tasas de mortalidad infantil más durables y elevadas del mundo (84), cuestión que confirmaría su representación como país subdesarrollado. En ese marco, un enfoque profiláctico y moralizador inspiró acciones puericulturales

(80) MCClintock (1993); VARIKAS (2007); YUVAL-DAVIS y ANTHIAS (1989).

(81) Palacios y LeYTON (2014). Los autores se refieren fundamentalmente a los trabajos de Augusto Orrego Luco, Ricardo Escobar y Pedro Gori.

(82) A fines del siglo XIX, el obstetra francés Adolphe Pinard la describía como el conocimiento científico sobre la reproducción, conservación y mejoramiento de las especies a partir del cuidado de las madres y los niños, especialmente en la época de la lactancia. LEYS STEPAN (1991).

(83) ILLANES (2007).

(84) La autora señala que entre 1871 y 1908 , las cifras de mortalidad infantil fluctuaron entre 273/1.000 a 340/1.000. Será solo hacia 1950 que Chile pudo afirmar haber superado la mortalidad infantil como problema nacional. 
articuladas por la representación corporal simbiótica de «la unidad madre-hijo». Naturalizando la responsabilidad del cuidado de los niños en las mujeres, el imperativo médico será inducir en ellas «y especialmente en las mujeres del pueblo, la lactancia de sus hijos, una cuestión que tendría necesidad de una vasta campaña de intervención educativa» (85).

Efectivamente, junto al Instituto de Puericultura fundado en 1906 y a la Gota de Leche abierta en 1911, la educación puericultural se impartió en escuelas, hospitales, fábricas y en los hogares mismos de «las madres populares». La convicción generalizada entre los médicos como Luis Calvo Mackenna, era que estas mujeres eran las responsables de «la vergüenza de nuestro país» (86): la mortalidad infantil. En esa línea, el Dr. Alcibíades Vicencio recalcará que en el Instituto de Puericultura se les enseñaría «a esas mujeres infelices e ignorantes a defenderse contra los peligros que pueden amenazar el desarrollo normal de su embarazo [...] [El Instituto lucha] por el predominio de nuestra raza. [En él se forjan] las mejores armas para nuestra guerra santa» (87).

Quienes transmitirán esta pedagogía encargada por la ciencia médica estatal, fueron las primeras mujeres profesionales del país: maestras, matronas, asistentes sociales. Efectivamente, Lavrín sostiene que la higiene social y las políticas puericulturales de la época que promovieron la prestigiosa idea de «la maternidad científica», levantaron dos agendas para las mujeres: enseñarles a otras mujeres cómo mejorar su rol de madres y servir al progreso de la nación como profesionales del cuidado. El discurso puericultural perfilaba, así, una misión civilizadora para «las buenas mujeres de la nación», encargadas desde ahora de «sanitizar y moralizar la esfera sexual con el fin de construir una nación saludable y fuerte» (88). El inédito protagonismo de estas mujeres en la escena pública, confirmará la idea de que «la mujer» era un factor clave para el cambio social: Lavrín sostiene que en los años 1920-1930 esta idea devendrá consenso entre el Estado higienista, las primeras mujeres profesionales y las feministas del cono sur.

Sin embargo, tal «patriotismo femenino» también tuvo implicancias paradójicas. El llamado civilizatorio intentará asimilar la alteridad representada por «la familia popular» de comienzos del siglo xx: familia heterosexual, pobre y racializada cuya imagen hegemónica incluía las caóticas figuras de un padre abandonador, alcohólico, violento y sexualmente desenfrenado; una madre abandonada, ignorante, supersticiosa y moralmente débil; y unos «hijos huachos» (89), futuros ciudadanos de la nación, cuyo desamparo reclamaría su integración a «la familia nacional».

(85) ILLANES (2007): 115.

(86) Calvo Mackenna en ILLANES (2007): 148.

(87) Vicencio en Illanes (2007): 127-128.

(88) LEYS STEPAN (1991): 81.

(89) En Chile, «huacho» es la denominación popular que hace referencia al hijo/a no reconocido/a por su padre. 
Para hacerse efectiva como encarnación de «la buena femineidad nacional», «la civilizadora» requirió de la otredad producida por las prácticas discursivas del Estado científico: «la madre popular», tal como señala Illanes, encarnando su misión, las civilizadoras promovieron a «la mujer popular»a la categoría de «madre» otorgándoles con ello, «una ciudadanía» (90). Quedaba así constituida la relación jerárquica entre la madre pobre, racializada, impúdica y responsable de las altas tasas de mortalidad infantil del país y «la civilizadora», cuyas «naturales» cualidades femeninas le permitirían «corregir los errores de las madres» (91).

La respuesta a la pregunta por quién define a las mujeres es así, paradójicamente puesta en acto por el agenciamiento de las civilizadoras, de entre las cuales muchas devendrán feministas. Encarnando las funciones de mediación y femineidad complementaria, ellas se encargarán de consolidar la representación viril y paternal del Estado como «buen padre» de la nación.

\subsection{El discurso feminista de «la superioridad moral de la mujer»}

Gran parte de los autores que han escrito sobre los orígenes del movimiento feminista chileno coinciden en localizar como hito clave la fundación del Círculo de Lectura en 1915, una agrupación de mujeres letradas de clase media cuya principal gestora fue la profesora Amanda Labarca (92). Sin embargo, es importante consignar que el sujeto del feminismo en el Chile de esta época no es en ningún caso homogéneo y que tanto feministas católicas como feministas obreras tuvieron una palabra pública al respecto (93). Sin posibilidad de profundizar en lo anterior, me interesa presentar dos claves de lectura en relación a nuestro problema: a) el relativo consenso feminista con respecto a la representación de «la mujer popular»; b) el uso del discurso de «la superioridad moral de la mujer» en la voz de las feministas liberales, letradas y de clase media: un uso estratégico exitoso que -sostengo- las consolida como el sujeto hegemónico del feminismo de la época. Al respecto, las primeras revistas, periódicos y escritos feministas de fines del XIX y comienzos del XX constituyeron un material de análisis del cual solo podré exponer algunos ejemplos (94).

(90) IllaNES (2007): 218.

(91) Calvo Mackenna en ILlanes (2007): 186.

(92) Lavrín (1995); Covarrubias (1978); Gaviola et al. (2007).

(93) Maza (1995); Hutchison (1992); Vitale y Antivilo (1999); Correa y Ruiz (2001).

(94) Fueron primero las mujeres de élite, cercanas al Partido Conservador y preocupadas de «la cuestión social» y luego aquellas debutantes de la clase media profesional, quienes fundaron las primeras revistas y periódicos de mujeres que serían antecedente y/o parte del movimiento feminista sufragista en Chile. Así se sucedieron El Eco de las Señoras, La Mujer, La Voz Femenina, Evolución, Acción Femenina, Revista Femenina, Nosotras, La Mujer Nueva. 
La figura de «la mujer popular» emerge de manera transversal en los discursos de feministas católicas de élite, obreras y liberales de la época. Así por ejemplo, buscando explicaciones a las situaciones de las que fue testigo en la Cruz Blanca (95), Adela Edwards (96) ponía el acento tanto en la falta de educación religiosa como en la explotación de la mujer que recibía «sueldos ínfimos», casi siempre «la mitad de lo que recibe un hombre, aunque ella trabaje igual o más», aunque sea casi siempre «quien sostiene a la familia» y el hombre quien «gasta todo en él mismo y en la taberna» (97).

Esta retórica es un buen ejemplo de las tensiones de una época en la cual es posible ver articuladas posturas conservadoras, puntos de vista feministas, estigmatizaciones de «la familia popular» y la persistente relación de alteridad entre «la civilizadora» y «la mujer popular» (insistentemente enunciada en tercera persona). Es esta «víctima de la prostitución» y de «esposos alcohólicos» la que legitima el agenciamiento de civilizadoras católicas como Edwards.

Sin embargo, cuando se trata del cuerpo y la sexualidad, «la mujer popular» emerge de manera no tan distinta en la retórica del movimiento obrero, incluido (aunque de manera tensionada) el discurso de las obreras feministas.

Analizando la prensa obrera de la época (98), Hutchison sostiene que la creciente participación laboral femenina a comienzos del siglo Xx trastornó los discursos de la política obrera, «concebida como actividad esencialmente masculina» (99). Amenazando los roles tradicionales de género (ya afectados por los efectos castradores de la explotación capitalista), «la mujer obrera» fue nombrada en la prensa como «hija del pueblo» y representada como víctima de los hombres capitalistas, quienes ya no podían manipular a los obreros sindicalizados. Asimismo, la representación más persistente de la fábrica fue la de un lugar amenazante para la salud física y sobre todo moral de «la mujer obrera»: «se pensaba que la dominación sexual, inherente a la relación jefe hombreempleadas mujeres, se debía evitar sacando a las mujeres de ese contexto» (100). Así, el estatuto de las mujeres como obreras era considerado indeseable y transitorio, reforzándose en cambio su representación como hijas, madres y esposas de obreros.

(95) Institución de caridad encargada de acoger a mujeres violadas, huérfanas, madres solteras y «víctimas de la prostitución». MAZA (1995).

(96) Mujer católica perteneciente a la élite económica del país, nieta de una de las mujeres más ricas del siglo XIX (Juana Ross de Edwards), fundadora de la Liga de Damas en 1912, de la Cruz Blanca en 1918, de la Acción Nacional de Mujeres de Chile (ANMCH) en 1932 y elegida regidora por Santiago en las elecciones municipales de 1935. MAZA (1995 y 1998).

(97) MAZA (1995): 171.

(98) Principalmente El Trabajo, El Socialista, El Alba, La Reforma, La Alborada, La Palanca y La Federación Obrera.

(99) Hutchison (1995): 125.

(100) HUTCHISON (1995): 129. 
Sin embargo, el auge de las sociedades mutualistas femeninas abrirá el problema de cómo reconciliar esta representación tradicional con la imagen de la mujer militante y revolucionaria. Es en este contexto que surge la prensa obrera feminista: La Aurora Feminista (Santiago, 1904), La Alborada (Valparaíso, 1905-1907) y La Palanca (Santiago, 1908) vehiculizarán la convicción de que «toda libertad será un fantasma mientras viva en esclavitud la mitad del género humano» (101).

No obstante, Hutchison sostiene que si bien la discriminación de género al interior del movimiento obrero fue tematizada en estas publicaciones (102), las feministas se sintieron en general presionadas a tranquilizar a sus compañeros eligiendo «la unidad de clase» (103).

Podemos apreciar esta paradoja existencial interseccional (104) que muestra la tensión entre la identidad feminista y la identidad obrera, en las retóricas de mujeres como Esther Valdés (105), quien intentando armonizar las demandas en favor de las mujeres y la demostración de lealtad a la lucha de clases, termina reforzando el estereotipo victimizante de «la mujer popular». Así, por ejemplo, si Valdés alentó al movimiento obrero a tomar una posición clara en relación a la emancipación de las mujeres, también usó estratégicamente el argumento de la «amenaza a la virtud femenina» para abogar por la jornada de 8 horas de trabajo, afirmando que aquello protegería a las jóvenes que volvían a su hogar en la noche. De igual modo, ella sostendrá que las obreras serían presas fáciles de sus patrones debido a su «inteligencia atrofiada por la rudeza del trabajo mecánico» (106). Así también, en el afán de defender la necesidad de educación, advertía:

Si la mujer no comprende en toda su extensión la misión que en la sociedad y en el hogar le corresponde, ¿no es acaso un enemigo inconsciente que tiene el hombre para realizar sus ideales de mejoramiento, mediante la organización gremial? [...] la lucha y la cooperación de la mujer serán estériles mientras nuestros protectores compañeros no nos eduquen convenientemente... (107).

Hutchison concluye así, que gran parte del feminismo obrero coincidió en que el objetivo a largo plazo era devolver a las mujeres a su «lugar natural» en

(101) La Alborada, 1906, en HutChison (1992): 18.

(102) Mujeres como Carmen Jeria, «Yedra» o Juana Roldán explicitaron en diversas ocasiones el conflicto asociado al alcoholismo y/o violencia de sus «compañeros», así como también la sospecha en torno al supuesto según el cual la emancipación de las mujeres sería resultado automático del éxito de la lucha obrera. Hutchison (1992).

(103) Hutchison (1992): 18.

(104) Tal como señalan CRENSHAw y BonIs (2005): 61, se trata de una «dimensión particular de la desposesión» ampliamente registrada en la historia del feminismo, a partir de la cual se obliga al individuo a separar su energía política entre dos proyectos supuestamente antagonistas.

(105) Líder de la Asociación de Costureras, colaboradora de La Alborada y posteriormente, directora de La Palanca.

(106) HutChISON (1992): 24.

(107) Hutchison (1992): 26. 
tanto protectoras del espacio doméstico. En palabras de Valdés, la mujer obrera encontraría «satisfacciones más puras [...] en su noble misión de hija, esposa y madre $[\ldots]$ y los hombres $[\ldots]$ alcanzarían a ser efectivos protectores y sostenes de sus familias» (108).

Finalmente, las voces de las feministas liberales son vitales al momento de revisar el que -sostengo- fue en esta época el uso estratégico más exitoso del discurso de «la superioridad moral de la mujer».

Los políticos radicales y liberales de fines del siglo XIX, sostenían que las mujeres eran demasiado incultas como para votar y en esa medida, su educación se presentaba como un requisito necesariamente anterior (109).

Las feministas que coincidían con esta ideología del progreso, confirmaron su visión lineal, ascendente y progresiva del tiempo, aunque a partir de otro tipo de argumentos. En efecto, la tarea materno-civilizadora de la educación de los futuros electores y el derecho a «cultivar el espíritu», fueron retóricas a partir de las cuales muchas de estas mujeres resignificaron el argumento de «la naturaleza diferente y complementaria de los sexos», defendiendo férreamente el derecho a la educación como parte de la idealización de «la pureza espiritual femenina» en oposición a la «suciedad» de la política masculina.

Así por ejemplo, Maza sostiene que el principal énfasis de un periódico como La Mujer (110), fue defender la idea de que las mujeres poseían enormes virtudes personales entre las que destacaba una sensibilidad mayor que la de los hombres. Así, los hombres no tenían por qué temer que «la mujer chilena siga el mismo rumbo que los otros países, en los cuales se habla como de cosa posible, de dictar leyes que permitan a la mujer tomar parte en el sufragio político; porque la mujer chilena ni quiere, ni aceptará tales prerrogativas, en su concepto detestables» (111).

En cambio, varios artículos se encargaron de sostener que

la mujer ejercía una forma superior de poder e influencia, porque estaba a cargo de la educación y formación moral de las nuevas generaciones de sufragantes [...] En vez de ambicionar el derecho al sufragio enseñe al hombre!, ella que es su maestra, a respetar su nombre, a ser digno i honrado; dé a la patria electores conscientes, desinteresados i nobles, que la felicidad i el progreso de los pueblos no depende del número de electores sino de la calidad de ellos (112).

Otro de los ejemplos paradigmáticos de este argumento según el cual la educación de las mujeres era un fin mucho más elevado que el sufragio, es ilustrado por Amanda Labarca. La primera vez que expresó su opinión acerca del

(108) Hutchison (1992): 28.

(109) Castillo (2009); Maza (1998).

(110) Publicación de la Academia Mercedes Marín del Solar, fundada en 1897 por la profesora Leonor Urzúa.

(111) La Mujer, 1897. MAZA (1998): 338.

(112) Ibidem. 
sufragio femenino en su libro Actividades femeninas en los Estados Unidos (1914), su planteamiento fue el siguiente:

No soi feminista militante, ni menos sufragista, porque ante todo soi chilena, i en Chile hoi no cabe la cuestión sufragista. Pedir el voto sería tan absurdo como si para vestir al desnudo principiáramos por ofrecerle una corbata de seda [...] $\mathrm{Si}$ llegásemos algún día a un grado de civilización igual al que hoi ostentan los Estados Unidos, Inglaterra o los países Escandinavos, la cuestión feminista fluiría sola [...]. La palabra feminista es entre nosotros sinónimo de ridiculez... (113).

Labarca agregaba, además, que el voto llevaría a las mujeres a «prestar su concurso a acciones que repugnan su delicadeza moral [...] para los hombres la política y el cohecho forman un matrimonio indisoluble» (114).

Es importante identificar esta retórica progresista que delimitaba «lo oportuno» de «lo inoportuno», bajo la convicción de una inclusión política lenta y progresiva de la mujeres. La frase «no soi feminista porque ante todo soi chilena» pareciera sugerir que el impulso feminista por «lo inoportuno», constituiría un interés antinacional. Las palabras de Labarca se inscriben además, en la idealización moral de «la mujer» como estrategia de autoafirmación: según su argumento, no se trataría de una incapacidad femenina, sino que al contrario, de la incapacidad de la política para acoger «la delicadeza» y la «superioridad moral femenina».

Sin embargo, como he podido constatar, este uso del discurso de «la superioridad moral de la mujer» se transforma bajo la configuración nacionalista de los años 1920-1930. Efectivamente, es cuando la misión civilizadora de «la mujer chilena» se consolida en el imaginario nacional, que las feministas liberales transforman este uso discursivo: en vez de servir como un justificativo para alejarse de la «sucia política», será utilizado para obtener la emancipación política representada por el derecho al voto.

La posibilidad del sufragio femenino constituía una amenaza para los varones radicales y liberales, convencidos de que si se les otorgaba derecho a voto, las mujeres votarían por el Partido Conservador (115). Es en este contexto que es necesario comprender los dos énfasis estratégicos que he identificado en el uso feminista liberal del discurso de «la superioridad moral de la mujer», ambos orientados a negociar con la ansiedad nacional al «desorden sexual»: a) confirmar el modelo legítimo (heterosexual, burgués y blanco-mestizo) de «familia nacional»; b) asegurar el carácter «femenino» del feminismo chileno.

En relación al primer énfasis, cabe destacar el análisis de Lavrín de los programas políticos de organizaciones, secciones femeninas de partidos progresis-

(113) MAZA (1998): 350-351, énfasis mío.

(114) Ibidem.

(115) MAZA (1995 y 1998). 
tas y partidos feministas de los años 1920-1930 (116). La autora concluye que junto con abogar por la igualdad de salarios y el sufragio femenino, gran parte de las demandas de las feministas liberales de la época fueron de corte higienista y se focalizaron en la defensa de «la mujer popular» a partir de: educación puericultural, tests prenupciales, erradicación de la pornografía, tratamiento obligatorio de enfermedades venéreas (cuyo agente se presuponía varón), defensa de la maternidad y la familia.

Tal como sostiene Amorós (117), asumiendo la necesidad de definirse por oposición a la hipocresía de la doble moral patriarcal, una gran parte del feminismo ilustrado «occidental», se caracterizó por un discurso moralizante. En el caso chileno, la inscripción del feminismo liberal en las políticas higienistas de «la maternidad científica» y su defensa de «la madre popular» frente al «padre popular» alcohólico, violento, abandonador y agente de contaminación sexual (con el claro sesgo de clase allí involucrado), le permitieron encarnar «la buena femineidad nacional».

En cuanto al carácter femenino del feminismo chileno, resulta sugerente revisar brevemente los argumentos de las publicaciones de la época. Estos enfatizaron su rechazo al «feminismo anárquico» que «robaría a las mujeres su encanto natural, convirtiéndolas en seres neutros, deshaciendo el balance de los sexos» (118). Afirmaron que «el feminismo adopta el carácter nacional de los países [...] [En Chile, las mujeres] nunca podrían ceder el sentido de la maternidad que rodea y penetra nuestra comprensión de la vida», y ya que este sentido las dotaba de una «sensibilidad especial», el sufragio respondería «a la necesidad [de las mujeres] de emprender una tarea amplia, apostólica de paz y armonía entre todas las clases sociales» (119). En Emancipación Civil, escrito por Amanda Labarca en 1925, la feminista se consagraba a tranquilizar a los hombres políticos: «si las mujeres pedimos equiparación civil no es porque intentemos el trágico esfuerzo de llegar a ser en todo vuestras semejantes [...]

(116) Tales como el Partido Femenino Progresista Nacional, el Partido Femenino Democrático, el Partido Cívico Femenino, el Bando Femenino, el Partido Femenino Nacional, el Partido Nacional de Mujeres, la Unión Femenina de Chile, el Consejo nacional de Mujeres, la Federación Unión Obrera Femenina. Una mención aparte la constituye el Movimiento Pro-Emancipación de la Mujer Chilena (MEMCH), fundado en 1935. Se trató del primer grupo político-reivindicativo feminista y de izquierda que logró masividad, radicalidad y continuidad en el tiempo. A pesar de que en términos de clase era más heterogéneo que el resto de los grupos feministas sufragistas de la época, sus principales líderes correspondieron al perfil letrado y de clase ya señalado. En 1935 el MEMCH ya abogaba por la necesidad de legalización del aborto, especialmente en nombre de «la mujer popular» para quien «la maternidad constituye una verdadera tragedia». Jiles (1992): 105. Otro ejemplo de radicalidad específicamente anticlerical lo constituyeron los «Centros femeninos de libre pensadoras Belén de Sárraga» fundados desde 1913 en el norte del país. Sin embargo estos tuvieron corta duración y comienzan a decaer a partir de 1918, con la caída de la explotación del salitre. GAviola et al. (2007).

(117) AMORós (1994).

(118) Acción femenina, 1922. LAVRín (1995): 292-293, énfasis mío.

(119) Nosotras, 1931. LAVRín (1995): 299-300, énfasis mío. 
solo queremos armonizar con vosotros en un plano de igualdad espiritual. Abominamos, tanto del hombre que se feminiza como de la mujer que adopta arrestos de varón» (120).

Feministas como Delia Ducoing (en su Charlas femeninas publicado en 1930), también rechazaron el «feminismo extranjero» de las londinenses por falso, masculino, provocador y «pasado de moda», ya que actualmente «el verdadero feminismo» consistía en un trabajo de «concientización de derechos, sentimientos maternales y admirable generosidad» (121).

Podemos constatar así, cómo esta defensa feminista del «encanto natural», la «sensibilidad maternal» y la «misión social, moral o apostólica», presenta la femineidad heteronormada, blanco-mestiza y de clase media como patrimonio nacional, en pos de una demanda de reconocimiento. En esa configuración nacionalista que apela a las virtudes civilizatorias de «las buenas mujeres de la nación», las feministas cercanas al Partido Liberal y Radical se toman en serio «la buena nueva» de un «patriotismo femenino», utilizando la defensa de la femineidad hegemónica como discurso estratégico de emancipación: para educar bien a los hijos de la patria, para desarrollar las cualidades espirituales de la nación, para incidir en la regeneración moral de la política.

\section{4. «LA SUPERIORIDAD MORAL DE LA MUJER» COMO NORMA RACIALIZADA DE LA FEMINEIDAD EN CHILE}

A lo largo del presente texto, he querido mostrar la emergencia contextual, disputada y contingente del discurso de «la superioridad moral de la mujer» en la configuración nacionalista de comienzos del siglo Xx en Chile. Sostuve que este acontecimiento dependió de dos eventos discursivos que localizo entre fines del XIX y comienzos del XX y que implicaron la transformación (nunca total y siempre tensionada) de dos representaciones: la del mestizaje (de la degeneración al orgullo racial) y la de «la mujer» (de la falla a la superioridad moral). Son estos dos eventos los que -modelándose mutuamente- configurarán el modelo género-racializado de «la familia nacional», el cual apela a la figura de «la civilizadora» en tanto representante de «la buena femineidad nacional» y complemento de la figura revirilizada del Estado-nación. Es en este marco que el discurso de «la superioridad moral de la mujer» se vuelve un consenso entre el Estado, las élites intelectuales y las voces de las feministas liberales, ilustradas y de clase media. Y es justamente en las voces de estas feministas que el discurso de «la superioridad moral de las mujeres» muestra los efectos paradójicos de las estrategias de inversión (122).

(120) Labarca en CASTILlo (2011): 16, énfasis mío.

(121) Ducoing en LaVRÍN (1995): 299-300.

(122) VARIKAS (2007). 
Siguiendo a Nietzsche, la estrategia de inversión apunta a «la sublevación histórica de los esclavos en la moral»: el estigma que los poderosos han construido sobre los débiles se invierte y se transforma en elección, en idealización de sí, en «orgullo paria» (123). En esa línea, Varikas señala que apelando a una revalorización positiva de aquello que ha sido subvalorado antes, la estrategia de inversión recurre al argumento de una «naturaleza»o «cultura» compartida para movilizar la unidad de «la diferencia» anteriormente excluida. Históricamente, el potencial subversivo de esta transmutación radical de los valores dominantes ha permitido crear movimientos políticos, subjetividades e identidades colectivas (124). Sin embargo, la estrategia de inversión no revierte la lógica binaria ni los términos en los que han sido definidos los valores, sólo invierte sus valorizaciones. Junto con ello, apelando a una supuesta «naturaleza compartida», la heterogeneidad de los sujetos es sacrificada en pos de la categoría esencializada.

Los dos eventos discursivos que he presentado aquí, pueden ser comprendidos a partir de esta estrategia. Efectivamente, tanto la rehabilitación moral de «la síntesis mestiza» como la de «la mujer» portan la huella de humillaciones históricas. Marcados por las ansiedades de los discursos médicos y letrados en torno al desorden sexual y racial, los cuerpos así alterizados exigen otras vías de reconocimiento distintas a la mera asimilación a los valores dominantes del blanqueamiento y la «falla» femenina. La configuración nacionalista de comienzos del siglo Xx en Chile recogerá estos malestares de manera ambivalente, proponiendo un modelo género-racializado de «familia nacional» políticamente más inclusivo que el de la Colonia y la Independencia, sin por eso dejar de apelar a una jerarquía higienista de los valores $($ limpio $=$ sano=bueno $=$ ordenado=blanco $/ \mathrm{mestizo}$ ) que reedita la misión civilizadora del colonialismo bajo la figura moderna del Estado, el buen padre que vendría a proteger a las madres populares y a los huachos de la nación.

Es respondiendo a este llamado de «la familia nacional» que el uso feminista del discurso de «la superioridad moral de la mujer» se devela paradójico: por una parte, las feministas desafían la simple mímesis al resignificar de manera estratégica el argumento modelado por el Estado y las élites intelectuales, con el objeto de promover nuevas formas de reconocimiento y autoestima colectiva y de obtener derechos civiles y políticos. Por otra parte, sin embargo, esta práctica discursiva no solo confirma los términos binarios, heteronormados y jerárquicos de la diferencia sexual, sino que también el carácter racializado de «la familia nacional».

Dicho de otra manera, el argumento apela a la idea de una «naturaleza»o patrimonio moral que no se repartiría de manera equitativa entre todas las mujeres, sino que pareciera constituir el privilegio de ciertas mujeres, en general de clase media, más blancas, letradas y civilizadas que 'otras' mujeres, cuyos

(123) NIETZSCHE (2000).

(124) VARIKAS (2007). 
derechos habría que defender y en nombre de las cuales habría que hablar. A partir de la racialización de la clase social, el discurso de «la superioridad moral de la mujer» se devela, de este modo, como una norma racializada de la femineidad (125) que (re)produce relaciones de poder entre mujeres. En esa medida, es la inteligibilidad v/s la irrealidad en tanto «mujer» lo que se juega para aquellas que no correspondan al modelo de «la buena femineidad nacional».

Así, los límites políticos del reconocimiento promovido por el discurso de «la superioridad moral» serán fundamentalmente dos. Por una parte, la producción de una jerarquía entre «las voces altas» de las mujeres blanco-mestizas que han negociado su rol subordinado en el orden de género y «las voces bajas» (126) de las mujeres empobrecidas y racializadas por ese mismo orden. Por otra parte, la producción de una retórica esencializada del «liderazgo femenino diferente» según la cual será necesario «permanecer femeninas» para tener algo que aportar a la política.

\section{BIBLIOGRAFÍA}

Amorós, C. (1994). Feminismo: igualdad y diferencia. México: Universidad Nacional Autónoma de México.

Anderson, B. (1993). Comunidades Imaginadas. Ciudad de México: Fondo de Cultura Económica.

Arancibia, P. (1986). Recepción y crítica a Raza Chilena: los comentarios de Miguel de Unamuno. Dimensión histórica de Chile, 3, 64-98.

Araya, C. (2006). La construcción de una imagen femenina a través del discurso médico ilustrado. Chile en el siglo XIX. Historia, 39 (I), 5-22.

Bengoa, J. (2000). Historia del Pueblo Mapuche. Siglos XIX y XX. Santiago: LOM.

Bhabha, H. (1994). El lugar de la cultura. Buenos Aires: Manantial.

Bidaseca, K. (2011). Feminismo y poscolonialidad. Descolonizando el feminismo desde y en América Latina. Buenos Aires: Ediciones Godot.

Boidin, C. (2008). Métissages et genre Dans les Amériques: des réflexions focalisées sur la sexualité. CLIO. Histoire, femmes et sociétés, (27). Disponible en: https:// clio. revues. org/7492 Disponible en: http://dx. doi. org/10. 4000/clio. 7492

Butler, J. (2006). Trouble dans le genre. Le féminisme et la subversion de l'identité. Paris: La Découverte.

Canguilhem, G. (1977). Idéologie et rationalité dans l'historire des sciences de la vie. Paris: Vrin.

Castillo, A. (2009). Estudio preliminar. Las aporías de un feminismo liberal: Martina Barros traductora de Stuart Mill. En M. Barros. Prólogo a La esclavitud de la mujer (pp. 7-36). Santiago: Palinodia.

(125) DORLIN (2005).

(126) BIDASECA (2011). 
(2011). Nudos Feministas. Santiago: Palinodia.

Castro-Gomez, S. (1996). Crítica de la razón latinoamericana. Barcelona: Puvill.

Correa, M. J. y Ruiz, O. (2001) Memoria de las mujeres: espacios e instancias de participación: Prensa Feminista, Centros anticlericales Belén de Sárraga y Teatro Obrero. Cyber Humanitatis, (19). Disponible en: http://www. cyberhumanitatis. uchile. cl/index. php/RCH/article/viewFile/8886/8733

Covarrubias, P. (1978). El movimiento feminista chileno. En P. Covarrubias y R. Franco. Chile: Mujer y sociedad (pp. 615-647). Santiago: Alfabeta.

Crenshaw, K. y Bonis, O. (2005). Cartographies des marges : intersectionnalité, politique de l'identité et violences contre les femmes de couleur. Cahiers du Genre (39), 51-82. Disponible en: http://dx. doi. org/10.3917/cdge. 039.0051

Dorlin, E. (2005). De l'usage épistémologique et politique des catégories de sexe et de race dans les études sur le genre. Les Cahiers du Genre, 39, 85-107. Disponible en: http://dx. doi. org/10. 3917/cdge. 039.0083

Foucault, M. (1969). L'Archéologie du savoir. Paris: Gallimard.

García de la Huerta, M. (1999). Reflexiones americanas: ensayos de intra-historia. Santiago: LOM.

Gaviola E., Jiles X., Lopresti L., Rojas C. (2007). Queremos votar en las próximas elecciones. Santiago: LOM.

Graham, R. (1990). The idea of Race in Latin America 1870-1940. Austin: University of Texas Press.

Guevara, T. (1911). Folklore Araucano. Santiago: Imprenta Cervantes.

Hall, S. (2010). Sin garantías. Colombia: Envión Editores.

Haraway, D. (1995). Ciencia, ciborgs y mujeres. La reinvención de la naturaleza. Valencia: Ediciones Cátedra.

Helg, A. (1990). Race in Argentina and Cuba, 1880-1930: Theory, Policies, and Popular Reaction. En R. Graham (ed.) The idea of Race in Latin America 1870-1940 (pp. 37-69). Austin: University of Texas Press.

Hobsbawn, E. (2010). Nacionalismo y nacionalidad en América Latina. En P. Sandoval (comp.). Repensando la subalternidad. Lima: Envion Editores.

Hutchison, E. (1992). El feminismo en el movimiento obrero chileno: la emancipación de la mujer en la prensa obrera feminista, 1905-1908. Documento de trabajo FLACSO, (80). Disponible en: http://www. sitiosur. cl/publicacionescatalogodetalle. php?PID $=3078 \&$ art $=$ Y \&autor $=\&$ colec $\operatorname{cion}=\& d o c=Y \& d o c 1=Y \& l i b=Y \&$ nunic $\mathrm{o}=15000021 \& \mathrm{rev}=\mathrm{Y} \&$ tipo $=$ ALL\&vid $=\mathrm{Y}$

- (1995). La defensa de las 'hijas del pueblo'. Género y política obrera en Santiago a principios de siglo. En L. Godoy et. al (eds.) Disciplina y Desacato: Construcción de Identidad en Chile, siglos XIX y XX (pp. 125-138). Santiago: Ediciones SUR y CEDEM.

Illanes, M. A. (2007). Cuerpo y sangre de la política. La construcción histórica de las visitadoras sociales (1887-1940). Santiago: LOM.

Jiles, X. (1992). De la Miel a los Implantes: Historia de las Políticas de Regulación de la Fecundidad en Chile. Santiago: Corporación de Salud y Políticas Sociales. 
Knight, A. (1990). Racism, Revolution and Indigenismo: México, 1910-1940. En R. Graham (ed.) The idea of Race in Latin America 1870-1940 (pp. 71-113). Austin: University of Texas Press.

Laqueur, T. (1992). La Fabrique du Sexe. Paris: Gallimard.

Lavrín, A. (1995). Women, Feminism and Social Change in Argentina, Chile and Uruguay: 1890-1940. Lincoln: University of Nebraska Press.

Leys Stepan, N. (1991). The Hour of Eugenics. Race, Gender, and Nation in Latin America. New York: Cornell University Press.

Márquez-Bretón, B. (1982). Orígenes del darwinismo en Chile. Santiago: Editorial Andrés Bello.

Maza,E. (1995). Catolicismo, anticlericalismo y la extensión del sufragio a la mujer en Chile. Estudios Públicos, 58, 137-197.

- (1998). Liberales, radicales y la ciudadanía de la mujer en Chile (1872-1930). Estudios Públicos, 69, 319-356.

McClintock, A. (1993). Family Feuds: Gender, nationalism and the family. Feminist Review, 44, 61-80. Disponible en: http://dx. doi. org/10. 1057/fr. 1993. 21; http:// dx. doi. org/10. 2307/1395196

Menard, A. (2009). Pudor y representación. La raza mapuche, la desnudez y el disfraz. Aisthesis, 46, 15-38. Disponible en: http://dx. doi. org/10. 4067/s071871812009000200002

Menard, A. \& Pavez, J. (2007). Mapuches y anglicanos. Vestigios fotográficos de la Misión Araucana de Kepe, 1896-1908. Santiago: Editorial Ocho Libros.

Murji, K. y Solomos, J. (2005). Racialization: Studies in theory and practices. NY: Oxford University Press.

Neri, M. (2004). Políticas de maternidad y maternalismo político: Buenos Aires (18901940). Buenos Aires: Biblos.

Nietzsche, F. (2000). La généalogie de la morale. Paris: Librairie Générale Française.

Palacios, C. y Leyton, C. (2014). Industria del delito. Historia de las ciencias criminológicas en Chile. Santiago: Ocholibros Editores.

Palacios, N. (1918). La Raza Chilena. Libro escrito por un chileno y para los chilenos. Santiago: Editorial Chilena.

Pavez, J. (2014). Imagen etnográfica y misión cristiana: sobre el registro del sexo/género en la colonización de Araucanía. Texto inédito.

Pakkasvirta, J. (2005). ¿Un continente, una nación? Intelectuales latinoamericanos, comunidad política y las revistas culturales en Costa Rica y el Perú (1919-1930). San José C. R: Editorial de la Universidad de Costa Rica.

Rama, A. (2009). La ciudad letrada. Madrid: Editorial Fineo.

Roa, A. (1974). Demonio y Psiquiatría. Santiago: Andrés Bello.

Robertson, E. (1984). Ideas nacional-socialistas en Chile, 1932-1938. Dimensión Histórica de Chile, 1, 92-129.

Rubio, P. (1996). Sobre el indigenismo y el mestizaje en la prosa de Gabriela Mistral. Taller de Letras (N. ${ }^{\circ}$ especial), 25-40.

Scott, J. (2001). Experiencia. La Ventana, 13, 43-73. 
(1998). La citoyenne paradoxale: les féministes françaises et les droits de l'homme. Paris: A. Michel.

Smith-Rosenberg, C. y Rosenberg, Ch. (1973). The female animal: medical and biological views of woman and her role in nineteenth-century America. The Journal of American history, 60 (2), 332-356. Disponible en: http://dx. doi. org/10. $2307 / 2936779$

Stoler, A. L. (2013). La chair de l'empire. Savoirs intimes et pouvoirs raciaux en régime colonial. Paris: La Découverte.

Subercaseaux, B. (2007). Historia de las ideas y de la cultura en Chile: Nacionalismo y cultura. Santiago: Editorial Universitaria.

Van Dijk, T. (2003). Ideología y discurso. Barcelona: Ariel.

Varikas, E. (2007). Les rebuts du monde. Paris: Stock.

- (2005). Lo que no somos. Historicidad del género y estrategias de desidentificación. Revista Internacional de Filosofía Política, 25, 77-88.

- (2006). Penser le Sexe et le Genre. Paris: PUF.

Vasconcelos, J. [1925] (1958). La Raza cósmica. Misión de la raza iberoamericana. En J. Vasconcelos. Obras completas. México D.F.: Editorial Libreros Mexicanos Unidos.

Veneros, D. (1995). Consideraciones médicas decimonónicas en torno a género, salud y educación. Dimensión histórica de Chile, 10, 135-153.

Vera, A. (2007). Desbanalizar el conflicto: mujeres conservadoras de elite y discursos de la diferencia en Chile actual. Revista de Estudios Interdisciplinarios Asosylf, 2, 25-35.

- (2009). Una crítica feminista a la madre pública postdictatorial: los discursos de género en la campaña presidencial de Michelle Bachelet. Revista Nomadías, 10, 111-129.

Vitale, L. y Antivilo, J. (1999). Belén de Sárraga. Santiago: CESOC.

Walby, S. (2000). Gender, Nations and States in a Global Era. Nations and Nationalism Journal of the Association for the Study of Ethnicity and Nationalism, 6 (4), 523540. Disponible en: http://dx. doi. org/10. 1111/j. 1354-5078. 2000. 00523. x

Yuval-Davis, N. y Anthias, F. (1989). Women-Nation-State . Londres: MacMillan. Disponible en: http://dx. doi. org/10. 1007/978-1-349-19865-8

Zárate, M. S. (2001). 'Enfermedades de mujeres': ginecología, médicos y presunciones de género. Chile, fines del siglo XIX. Pensamiento Crítico. Revista electrónica de historia, (1). Disponible en: http://www. memoriachilena. cl/archivos2/pdfs/ MC0023709. pdf

Zermeño-Padilla, G. (2008). Del mestizo al mestizaje: arqueología de un concepto». Revista Memoria y Sociedad, 12 (24), 79-95. 